\title{
Spectroscopic Detection of Active Species on Catalytic Surfaces: Steady-State versus Transient Method
}

\author{
Nobutaka Maedaa ${ }^{a}$ Fabian Meemkenª, Konrad Hungerbühlera , and Alfons Baiker ${ }^{\star a b}$
}

\begin{abstract}
Discrimination between active and spectator species is an important and demanding task in catalysis research. A comparative study of the Pd-catalyzed $\mathrm{CO}$ hydrogenation using in situ diffuse reflectance IR Fourier transform spectroscopy (DRIFTS) in steady-state and dynamic (transient) experiments shows that the information on surface species differs significantly depending on the type of experiment. In order to discriminate between active species and spectator species not involved in the surface reactions, DRIFTS was combined with a transient technique, modulation excitation spectroscopy (MES). This approach allows the detection of surface species responding to a specific periodic external stimulus, i.e. achieved by concentration modulation, and thereby offers excellent potential to unveil features of the surface processes, which are not accessible by steady-state experiments. However, the example of $\mathrm{CO}$ hydrogenation shows that the perturbation imposed to the system has to be chosen properly to benefit from the transient technique. Modulation of the $\mathrm{CO}$ concentration did not provide deeper insight into the reaction mechanism, whereas periodic changes of the hydrogen concentration provided valuable information concerning the active surface species and the reaction pathway. The study revealed that only a small fraction (about $4 \%$ ) of $\mathrm{CO}$ molecules adsorbed on specific Pd sites reacted with hydrogen, while the majority of adsorbed $\mathrm{CO}$ was inactive. The inactive $\mathrm{CO}$ molecules overwhelmingly contributed to the spectra measured under steady-state conditions.
\end{abstract}

Keywords: CO hydrogenation - Diffuse reflectance infrared spectroscopy - Heterogeneous catalysis . In situ spectroscopy · Modulation excitation spectroscopy

\section{Introduction}

Heterogeneous catalysis is one of the key technologies for realizing sustainable development and environmental protection. The global demand for innovative breakthroughs of efficient and environmentally benign catalytic systems spurs both industrial and academic research. Rational design of catalytic materials on the nano-/micro-scale requires a proper understanding of the interrelationship between structural and chemical properties of the materials and their catalytic behaviour. Today, a great variety of spectroscopic methods ${ }^{[1]}$ are applied in catalysis research, among which vibrational spectroscopies, ${ }^{[2-4]}$ particularly infrared spectroscopy, stand out due to their versatility

${ }^{*}$ Correspondence: Prof. Dr. A. Baiker ${ }^{\mathrm{ab}}$ E-mail: alfons.baiker@chem.ethz.ch alnstitute for Chemical and Bioengineering Department of Chemistry and Applied Biosciences ETH Zurich, Wolfgang-Pauli-Strasse 10 $\mathrm{CH}-8093$ Zürich

${ }^{\text {b} C h e m i s t r y ~ D e p a r t m e n t, ~ F a c u l t y ~ o f ~ S c i e n c e, ~}$ King Abdulaziz University, P.O. Box 80203, Jeddah 21589, Saudi Arabia and widespread use. Transmission IR spectroscopy (TIRS), diffuse reflectance IR Fourier transform spectroscopy (DRIFTS) and IR reflection-absorption spectroscopy (IRRAS) are suitable methods for monitoring adsorbed molecules at catalytic solidgas interfaces, ${ }^{[5,6]}$ while attenuated total reflection IR spectroscopy (ATR-IR) proved to be powerful for investigating catalytic solid-liquid interfaces.[7] Generally all these IR methods can be used in situ allowing the acquisition of information on the catalytic interface under reaction conditions. However, a problem arises if signals from 'real' active species have to be discriminated from spectator species not involved in the catalytic surface processes.

For selective extraction of information on active species, transient spectroscopic techniques have been developed such as steady-state isotopic transient kinetic analysis (SSITKA) $)^{[8-11]}$ and modulation excitation spectroscopy (MES). ${ }^{[12,13]}$ SSITKA operates at the chemical steady-state, but isotopic unsteady-state. Its combination with DRIFTS and on-line mass spectrometry is a powerful tool for investigating the relationship between dynamically changing surface species and gas-phase components on the same time-scale, leading to a deeper understanding of the involvement of surface species in catalytic cycles.[11] MES operates under unsteady-state con- ditions forced by periodic perturbation of the system by changing an external parameter, e.g. concentration, temperature, irradiation, or $\mathrm{pH} .^{[12]}$ This transient method facilitates selective detection of surface molecules responding to an external perturbation, enhancement of the signal-tonoise $(\mathrm{S} / \mathrm{N})$ ratio and extraction of kinetic information by phase sensitive detection (PSD). ${ }^{[13]}$ Here we present a comparative in situ IR study of the Pd-catalyzed hydrogenation of $\mathrm{CO}$ using steady-state and dynamic experiments. We demonstrate enhancement of the spectral resolution by MES and PSD, and show the importance of the proper selection of the external stimulation for gaining information on 'true' active species.

\section{Experimental}

A home-built in situ DRIFTS cell was employed for MES experiments. ${ }^{[6]}$ The design of the cell allows the detection of IR signals originating from diffuse reflectance at the catalyst surface while minimizing IR absorption by gas-phase components. The inlet of the cell was connected to an air-actuated Valco valve for switching gas feeds. The concentrations in the effluent gas were monitored using an on-line mass spectrometer (Pfeiffer 
Vacuum, ThermoStar ${ }^{\mathrm{TM}}$ ). DRIFT spectra were measured on a Bruker Equinox 55 FT-IR spectrometer equipped with a liquid nitrogen cooled MCT detector at $4 \mathrm{~cm}^{-1}$ resolution. MES experiments were carried out by periodically switching between two different gas atmospheres, either $\mathrm{CO} / \mathrm{H}_{2} \leftrightarrow$ $\mathrm{H}_{2}$ or $\mathrm{CO} / \mathrm{H}_{2} \leftrightarrow \mathrm{CO}$, where the $\mathrm{CO} / \mathrm{H}_{2}$ mixture contained $\mathrm{CO}$ and $\mathrm{H}_{2}$ in a ratio of $1: 3$ (5 vol\% $\mathrm{CO}$ and $15 \mathrm{vol}_{2}^{2} \mathrm{H}_{2}$ in He balance and $5 \mathrm{vol} \% \mathrm{H}_{2}$ or $\mathrm{CO}$ in $\mathrm{He}$, respectively). For each MES measurement, the cycles were repeated seven times, and the last four cycles were averaged to enhance the $\mathrm{S} / \mathrm{N}$ ratio. The acquired time-domain spectra were mathematically treated by PSD according to:

$$
A_{k}(\tilde{v})=\frac{2}{T} \int_{0}^{T} A(t, \tilde{v}) \sin \left(k \omega t+\varphi_{k}\right) d t,
$$

where $\mathrm{T}$ is the length of a cycle (modulation period), $\omega$ is the demodulation frequency, $\phi_{k}$ is the demodulation phase angle, $\mathrm{k}$ is the demodulation index $(\mathrm{k}=1$ in this study), and $\mathrm{A}(\mathrm{t}, \tilde{\mathrm{V}})$ and $\mathrm{A}_{\mathrm{k}}(\tilde{\mathrm{V}})$ are the active species responses in time- and phase-domain, respectively.

To compare results extracted from steady-state and dynamic experiments, we employed the hydrogenation of carbon monoxide on a $4 \mathrm{wt} \% \mathrm{Pd} / \mathrm{CeO}_{2}$ catalyst. The catalyst was prepared using a conventional impregnation method according to a protocol reported in ref. [14]. The mean $\mathrm{Pd}$ particle size of this catalyst is $3-4 \mathrm{~nm}$. Prior to use, the catalyst was subjected to $\mathrm{O}_{2}$-treatment at $723 \mathrm{~K}$ for 1 hour, and then to reduction with $\mathrm{H}_{2}$ at $573 \mathrm{~K}$ for 1 hour. This procedure was applied to suppress the formation of a thin layer of $\mathrm{Ce}_{2} \mathrm{O}_{3}$ on the $\mathrm{Pd}$ particles which is known to cause Strong Metal-Support Interaction (SMSI). ${ }^{[14]}$

\section{Results and Discussion}

\section{Sensitivity Enhancement}

The elucidation of the dynamic surface processes that occur during a solidcatalyzed reaction requires in situ IR spectroscopy with excellent time-resolution. However, the time-resolved spectroscopic approach results in an inherent trade-off between time-resolution and signal to noise $(\mathrm{S} / \mathrm{N})$ ratio; rapid spectral scans lead to low $\mathrm{S} / \mathrm{N}$ ratio, that means high noise level hiding the absorption bands of interest. This problem can be partly overcome by averaging FT-IR spectra from several scans. One of the key features of MES is that it utilizes a quasi steady-state response of chemical species to a periodic external stimulation. After several cycles, chemical processes reach a quasi steady-state, and each cycle gives rise to identical IR spec- tra, which enable all the stable cycles to be integrated into one cycle to achieve a high $\mathrm{S} / \mathrm{N}$ ratio. For illustration we may consider $\mathrm{CO}$ adsorption on the $\mathrm{Pd} / \mathrm{CeO}_{2}$ catalyst and subsequent reduction with hydrogen. Fig. 1a displays conventional spectra during $\mathrm{H}_{2}$ reduction of the CO-covered $\mathrm{Pd}$ surface. To achieve high time-resolution, the spectra were recorded by co-adding eight scans at a spectral resolution of $4 \mathrm{~cm}^{-1}$ and a scanning velocity of $80 \mathrm{kHz}$. In this manner, each spectrum could be recorded in $1.9 \mathrm{~s}$. The spectral acquisition at this timeresolution affords a very poor $\mathrm{S} / \mathrm{N}$ ratio, and even $\mathrm{CO}$ adsorbed on $\mathrm{Pd}$ can barely be detected at around $2000 \mathrm{~cm}^{-1}$. The high noise level makes it almost impossible to properly assign the bands and analyze the kinetics during the hydrogen exposure. By exploiting one of the principles of MES, the $\mathrm{CO}$ adsorption-hydrogenation cycle was repeated seven times, and the last four cycles were integrated into one cycle to enhance the $\mathrm{S} / \mathrm{N}$ ratio (Fig. 1b). Note that the noise level decreased considerably, leading to a more feasible band assignment. Two sharp bands assigned to on-top and bridged-CO on $\mathrm{Pd}(100)$ can be identified at 2060 and $1965 \mathrm{~cm}^{-1}$, respectively. To further enhance the $\mathrm{S} / \mathrm{N}$ ratio, the time-domain spectra were transformed to phasedomain spectra (Fig. 1c) using the relation given in Eqn. (1). Because the noise signal does not follow the periodic changes of the external stimulation, ${ }^{[13]}$ application of PSD allows the removal of most of the noise from the IR spectra and a spectral acquisition with high sensitivity down to $10^{-5}$ absorbance is achieved. The data were plotted at each $\phi^{\mathrm{PSD}}=10^{\circ}$ step; $0-170^{\circ}$ for the $\mathrm{CO}$ adsorption and $180-350^{\circ}$ for the $\mathrm{H}_{2}$ exposure. Note that in the phase-domain spectra, an additional broad band at ca. $1850 \mathrm{~cm}^{-1}$ assigned to bridged $\mathrm{CO}$ on $\operatorname{Pd}(111)^{[14]}$ is observable.

\section{Steady-state versus Transient Methods}

In this section, we demonstrate the spectral separation of active species from spectators by comparing steady-state reaction and concentration modulation conditions. Catalytic active sites frequently only comprise a small fraction of the whole surface sites. Therefore, the selective extraction of information on active sites/species requires careful data analysis. PSD was shown to be a powerful tool to separate IR signals of spectator species which do not respond to the external stimulus, i.e. the modulated reactant concentration. ${ }^{[13]}$

Fig. 2a shows in situ IR spectra during steady-state $\mathrm{CO}-\mathrm{H}_{2}$ reaction $\left(\mathrm{H}_{2} / \mathrm{CO}=\right.$ 3) on $\mathrm{Pd} / \mathrm{CeO}_{2}$ at $413 \mathrm{~K}$. As previously reported, several absorption bands emerged; sharp bands of on-top and bridged CO on $\operatorname{Pd}(100)$ facets at 2060 and $1965 \mathrm{~cm}^{-1}$, a

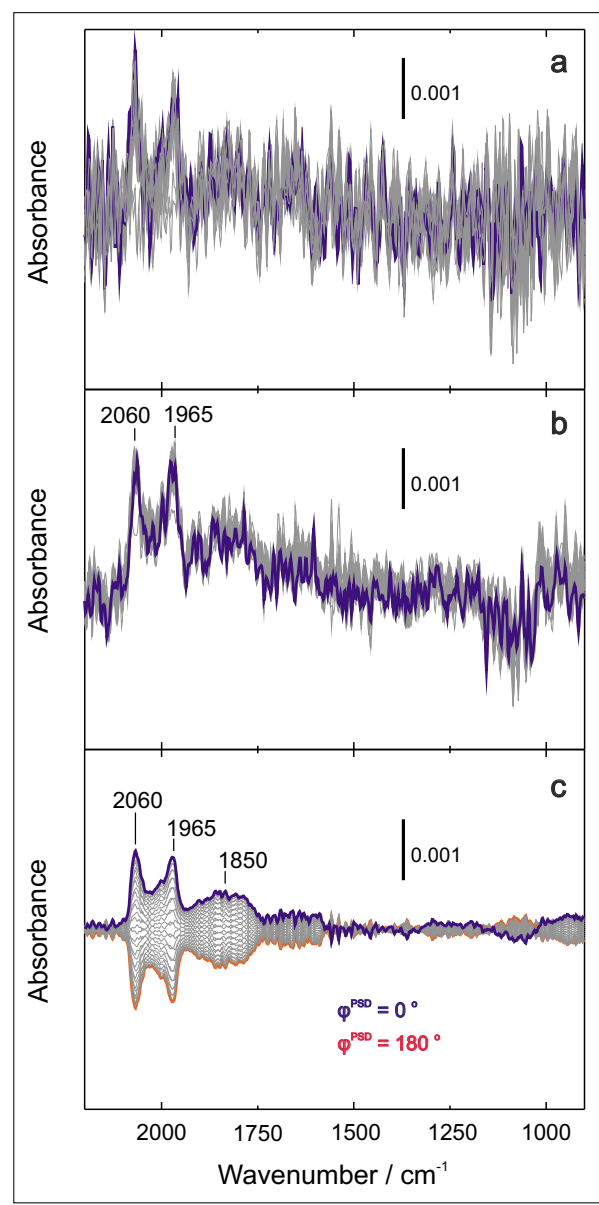

Fig. 1. $\mathrm{CO}$ adsorption on $\mathrm{Pd} / \mathrm{CeO}_{2}$ at $573 \mathrm{~K}$ and subsequent reduction with hydrogen. In situ IR spectra during switching between $\mathrm{CO}$ and $\mathrm{H}_{2}$ in time-domain with (a) 1 cycle, (b) 4 cycles, and (c) phase-domain. Conditions are given in experimental part.

broad band of bridged $\mathrm{CO}$ on $\operatorname{Pd}(111)$ facets at around $1900 \mathrm{~cm}^{-1}$, asymmetric and symmetric stretching modes of carbonate and formate species overlapping at 1250 $1700 \mathrm{~cm}^{-1}$, and weak bands assigned to the $\mathrm{C}-\mathrm{O}$ stretching mode of methoxide species at around $1100 \mathrm{~cm}^{-1} \cdot{ }^{[14]}$ All the absorption bands grew continuously and reached a steady-state after about $120 \mathrm{~min}$. The bands present after $120 \mathrm{~min}$ had elapsed are considered to reflect the steady-state surface composition of active and spectator species during the $\mathrm{CO}$ hydrogenation. To compare the steady-state with the transient method, $\mathrm{CO}$ adsorption and desorption cycling in the presence of $\mathrm{H}_{2}$, i.e. $\mathrm{CO}$ modulation $\left(\mathrm{CO} / \mathrm{H}_{2} \leftrightarrow \mathrm{H}_{2}\right)$ after 120 min of $\mathrm{CO}-\mathrm{H}_{2}$ reaction was repeated for MES and PSD, and the IR spectra were plotted as phase-domain and time-domain spectra as shown in Figs $2 b$ and c. As emerges from these data, formate, carbonate and methoxide species detected under steady-state remained virtually unchanged by modulating the $\mathrm{CO}$ concentration. Besides, all the CO on Pd(100), indicated by the bands at 2060 and $1965 \mathrm{~cm}^{-1}$, simply adsorbed and desorbed repeatedly. The broad band at 


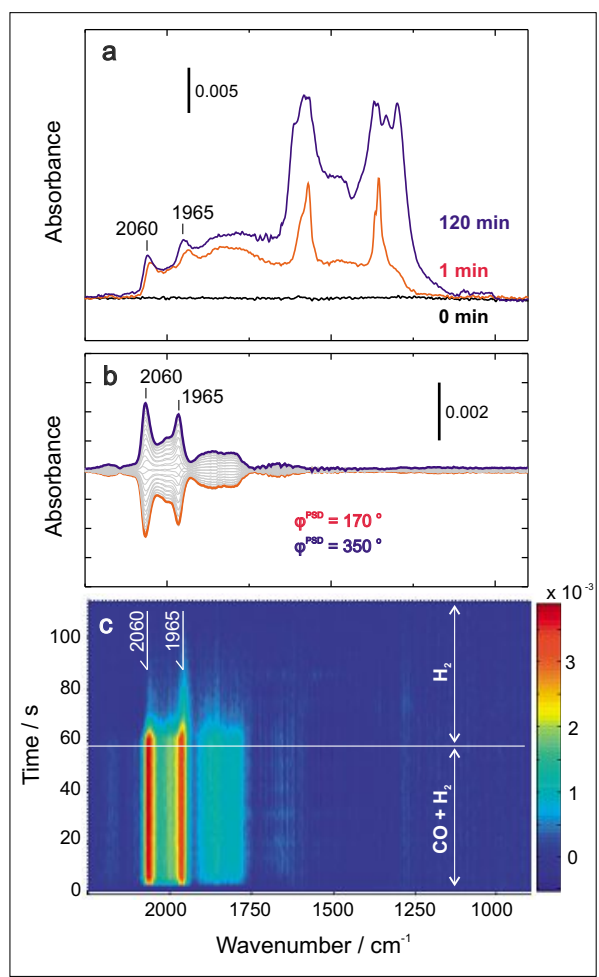

Fig. 2. In situ IR spectra during (a) steadystate $\mathrm{CO}-\mathrm{H}_{2}$ reaction on $\mathrm{Pd} / \mathrm{CeO}_{2}$ at $413 \mathrm{~K}$. (b) phase-domain and (c) time-domain spectra of CO adsorption-desorption $\left(\mathrm{CO} / \mathrm{H}_{2} \leftrightarrow \mathrm{H}_{2}\right)$ on $\mathrm{Pd} / \mathrm{CeO}_{2}$ exposed to $\mathrm{CO}-\mathrm{H}_{2}$ reaction atmosphere for $120 \mathrm{~min}$. Conditions are given in experimental part.

around $1900 \mathrm{~cm}^{-1}$ (CO on $\left.\operatorname{Pd}(111)\right)$ seemed rather stable and only decreased to half of its intensity upon desorption forced by the modulation. Time-domain spectra (Fig. 2c) indicate that the desorption process occurred slowly for bridged $\mathrm{CO}$ on $\mathrm{Pd}(100)$ at $1965 \mathrm{~cm}^{-1}$. ${ }^{[14]}$

As emerges from Fig. 2, the information on surface species gained by steady-state and transient methods differs significantly. The steady-state experiment detected both active and spectator species accumulated on the surface, while the CO modulation experiment provided mainly information on the adsorption-desorption dynamics of adsorbed $\mathrm{CO}$.

The most widely applied steady-state method has proven to be useful to characterize the overall surface properties of catalytic materials, e.g. surface properties such as acidity, composition, and structure, while the transient method facilitates the detection of surface molecules which are sensitive to the perturbation, that is, the system changes imposed by periodic variation of the external stimulus. Hence, application of both methods results in complementary information. However, it should be stressed that the application of a transient method does not always result in a gain of information on 'true' active species, as the results of $\mathrm{CO}$ modulation indicate. Note that the spectra resulting from $\mathrm{CO}$ modulation (Fig. 2b) are almost identical to those of the $\mathrm{CO}$ adsorptionhydrogen reduction sequence presented in Fig. 1c. The $\mathrm{CO}$ modulation experiment only revealed the simple $\mathrm{CO}$ adsorptiondesorption cycle, which is not of primary interest for elucidating the active species in the catalytic surface reaction. The surface coverage of $\mathrm{CO}$ changed only relatively little during $\mathrm{CO}$ modulation due to strong adsorption of $\mathrm{CO}$. This indicates that a proper choice of the perturbation of the system is of paramount importance for successful application of transient techniques. The perturbation (stimulation) has to be chosen in such a way that its response contains information on the targeted process. In the next section, the importance of the selection of the kind of external stimulus will be considered.

\section{Selection of an External Stimulation}

Obviously, injudicious application of transient spectroscopic techniques does not warrant the extraction of crucial information on the dynamic processes that occur during a catalytic reaction. Transient experiments that can stimulate the species actively involved in the catalytic cycle need to be employed. Naito et al. reported that several surface species were observed by in situ IR spectroscopy during $\mathrm{CO}-\mathrm{H}_{2}$ reaction over $\mathrm{Pd} / \mathrm{CeO}_{2} ; \mathrm{CO}$ on $\mathrm{Pd}(100)$ and $\operatorname{Pd}(111)$, carbonate, formate and methoxide species. ${ }^{[14-16]}$ Scheme 1 shows a feasible reaction pathway for methanol formation from $\mathrm{CO}$ and $\mathrm{H}_{2}$ via two adsorbed intermediate species, $\left[\mathrm{HCOO}^{*}{ }_{(\mathrm{a})}\right.$ (formate) and $\left[\mathrm{CH}_{3} \mathrm{O}\right]^{*}$ (methoxide). $\mathrm{CO}$ and $\mathrm{H}_{2}$ adsorb on the Pd surface, and react with the involvement of surface $\mathrm{OH}$ groups of the ceria support to formate which in consecutive steps is reduced to methoxide, and finally to methanol. Hydrogen is involved in all these consecutive steps, while CO is only involved in the first step. Furthermore, $\mathrm{CO}$ is more strongly adsorbed on Pd than hydrogen and thus partially blocks sites which would be available for hydrogen adsorption. As a consequence, when the con-

$$
[\mathrm{CO}]_{(\mathrm{g})} \leftrightarrows[\mathrm{CO}]_{(\mathrm{a})} \stackrel{\mathrm{H}_{(\mathrm{a})}}{\longrightarrow}\left[\mathrm{HCOO}_{(\mathrm{a})}^{*} \stackrel{\mathrm{H}_{(\mathrm{a})}}{\longrightarrow}\left[\mathrm{CH}_{3} \mathrm{O}\right]_{(\mathrm{a})}^{*} \stackrel{\mathrm{H}_{(\mathrm{a})}}{\longrightarrow}\left[\mathrm{CH}_{3} \mathrm{OH}\right]_{(\mathrm{a})} \leftrightarrows\left[\mathrm{CH}_{3} \mathrm{OH}\right]_{(\mathrm{g})}\right.
$$

Scheme 1. Proposed simplified reaction scheme for methanol formation from $\mathrm{CO} / \mathrm{H}_{2}$ over $\mathrm{Pd} /$ $\mathrm{CeO}_{2}$. Note that the first step (formate formation) involves surface $\mathrm{OH}$ groups from the partially reduced ceria support. ${ }^{[17]}$ Subscript (a) indicates absorbed species

centration of $\mathrm{CO}$ is modulated, it mainly affects the adsorption-desorption of $\mathrm{CO}$ (Figs 2b and c), while its further reaction to methanol is only weakly affected. Therefore, modulation of $\mathrm{H}_{2}$ concentration $\left(\mathrm{CO} / \mathrm{H}_{2} \leftrightarrow \mathrm{CO}\right)$ was required to probe the whole catalytic cycle.

Fig. 3 shows the concentration profiles of the various species during the $\mathrm{H}_{2}$ modulation experiment at $413 \mathrm{~K}$. Note the similar time-dependence of the hydrogen concentration changes and the methanol production curve. $\mathrm{CH}_{4}$ was barely detectable, indicating high selectivity to methanol of the catalyst under the conditions used. Under this transient condition $\left(\mathrm{CO} / \mathrm{H}_{2} \leftrightarrow \mathrm{CO}\right)$, in situ IR spectra were taken at a time resolution of $1.9 \mathrm{~s}$, and converted by PSD into phase-domain spectra (Fig. 4) to enhance the signal-to-noise (S/N) ratio. Strikingly, compared to the steady-state experiment shown in Fig. 2a, the intensity of all bands decreased by ca. $96 \%$, i.e. $0.005 \rightarrow 0.0002$ absorbance. This indicates that roughly only about $4 \%$ of the surface species that were observed in Fig. 1a, were directly involved in the methanol formation, and the rest

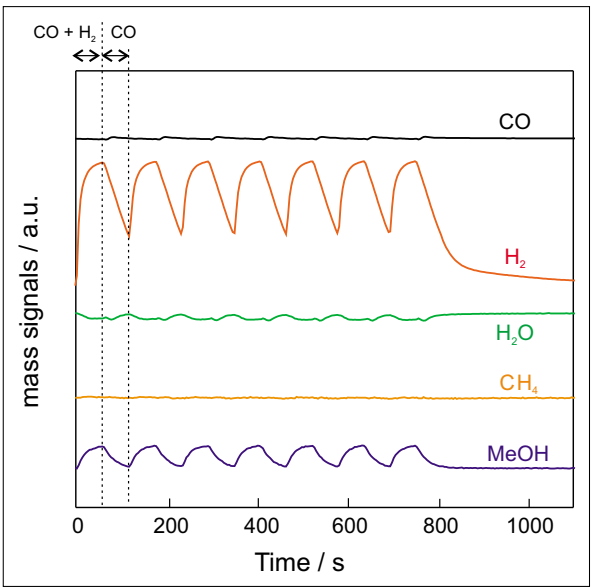

Fig. 3. Mass spectroscopic signals of gasphase components during transient reaction condition $\left(\mathrm{CO} / \mathrm{H}_{2} \leftrightarrow \mathrm{CO}\right)$ at $413 \mathrm{~K}$.

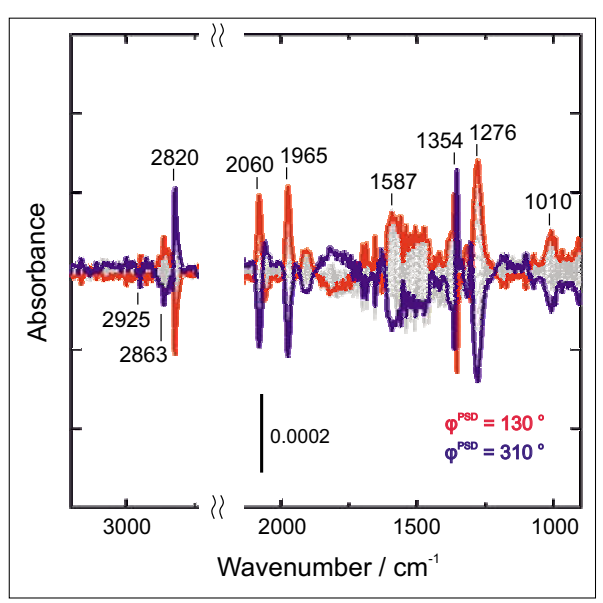

Fig. 4. Phase-domain spectra of active surface species under transient reaction condition $\left(\mathrm{CO} / \mathrm{H}_{2} \leftrightarrow \mathrm{CO}\right)$ at $413 \mathrm{~K}$. 
behaved as spectator species, being stabilized on the catalyst surface. An inspection of the phase-resolved spectra gives interesting insight into the reaction pathway of methanol formation. In the presence of $\mathrm{H}_{2}$ $\left(\phi^{\mathrm{PSD}}=350-190^{\circ}\right)$, several surface species showed negative absorbance as highlighted by the blue line (in-phase angle, $\phi^{\mathrm{PSD}}$ $=310^{\circ}$ ); methoxide species $(2925,2863$, $\left.1010 \mathrm{~cm}^{-1}\right), \mathrm{CO}$ on $\mathrm{Pd}(100)(2060,1965$ $\left.\mathrm{cm}^{-1}\right)$, carbonate $\left(1587,1276 \mathrm{~cm}^{-1}\right)$. These negative bands prove that all these species were consumed in the hydrogenation reaction to methanol. Interestingly, formate species showed an opposite trend; they appeared in the presence of $\mathrm{H}_{2}$, while they disappeared in the absence of $\mathrm{H}_{2}\left(\phi^{\mathrm{PSD}}=\right.$ $\left.170-10^{\circ}\right)$. This trend implies that the formation of formate species occurs rapidly, but its hydrogenation to methoxide species proceeds relatively slowly, hence being left on the surface at $\phi^{\mathrm{PSD}}=350-190^{\circ}$. While the CO-modulation experiment provided insight into the adsorption-desorption behavior of $\mathrm{CO}$ on the catalyst surface, the $\mathrm{H}_{2}$ modulation allowed some insight to be gained into the interdependence of formate, methoxide and methanol species.

The present study indicates that in situ IR spectroscopic studies under steady-state and dynamic (transient) conditions provide different IR spectra, which may lead to different conclusions. While spectroscopic investigations under steady-state conditions were found to be useful for characterizing stable surface species, transient conditions were a necessary prerequisite for detecting 'true' active species directly involved in the catalytic cycle. Previously it was proposed, based on steady-state measurements, that $\mathrm{CO}$ adsorbed on $\mathrm{Pd}(111)$ are the active sites for methanol formation on this catalyst. This proposal was based on the observation that methanol formation showed an induction period ( $c a .1$ hour) caused by gradual removal of a contaminating ceria layer on Pd (SMSI state) by $\mathrm{H}_{2} \mathrm{O}$ over $\mathrm{Pd}(111)$. The gradual removal of the ceria layer resulting in increasing exposure of the $\operatorname{Pd}(111)$ surface was proposed to be at the origin of the observed change of the catalyst selectivity from methane to methanol. Note that the transient method applied here gives different insight into the dynamic surface processes; the timedependent changes observed for $\mathrm{CO}$ adsorbed on $\operatorname{Pd}(100)$, formate, methoxide and methanol clearly indicate that these species are interdependent, in accordance with Scheme 1. Obviously, the application of steady-state and dynamic methods leads to different conclusions as regards the active sites.

As emerges from Fig. 4, the absorbance of active species is in the range of $10^{-4}-10^{-5}$ absorbance, which is below the detection limit of conventional IR spectroscopic methods. Therefore, the application of transient spectroscopic techniques such as MES/PSD to heterogeneous catalysis research is a powerful tool to give a more detailed insight into reaction steps involved in a catalytic cycle. The study also indicates that the type of transient reaction conditions or external perturbation parameters needs to be carefully selected to maximize the information that can be gained from such experiments. $\mathrm{CO}$ concentration modulation as an external stimulation merely resulted in oscillation of the amount of adsorbed $\mathrm{CO}$, but did not uncover the active species involved in the methanol formation. Only $\mathrm{H}_{2}$ modulation experiments gave information on the interdependence of surface species involved in the $\mathrm{CO}-\mathrm{H}_{2}$ reaction.

Finally, it should be mentioned that the successful application of MES and PSD has recently been extended to in situ X-ray absorption spectroscopy (XAS). Ferri and co-workers ${ }^{[18]}$ investigated the oxidation of methane on Pd-based catalysts using steady-state and transient in situ XAS. PSD applied to quick extended X-ray absorption fine structure (QEXAFS) data allowed significant insight to be gained into the fate of the Pd constituent during cyclic reduction-oxidation conditions $\left(\mathrm{CH}_{4} \leftrightarrow\right.$ $\mathrm{CH}_{4} / \mathrm{O}_{2}$ ). In principle the MES/PSD technique can be applied in combination with several other spectroscopic methods in catalysis research and its use may greatly expand their potential and application range.

\section{Conclusion}

We have illustrated the significance of high time-resolution, enhanced $\mathrm{S} / \mathrm{N}$ ratio, and discrimination between active and spectator species achieved by applying MES and PSD for in situ DRIFTS investigations using the hydrogenation of $\mathrm{CO}$ on $\mathrm{Pd} / \mathrm{CeO}_{2}$ as an example. By combining these methods with a conventional in situ DRIFTS set-up, an absorbance of $10^{-5}$ for surface molecules on catalytic materials was detectable. The comparative spectroscopic study under steady-state and transient conditions allowed the discrimination between active and spectator species on the catalyst surface. The generally low surface concentration of the active species can cause great difficulties in the interpretation of spectra resulting from steady-state measurements and may lead to different interpretation. Applying dynamic experiments can alleviate this difficulty. Particularly the combination of MES with PSD has proven to be a very efficient tool for extracting information normally not accessible by steady-state methods. However, injudicious application of MES and PSD may not lead to deeper insight into the reaction mechanism, as illustrated by the application of $\mathrm{CO}$ concentration modulation in the hydrogenation of $\mathrm{CO}$.

\section{Acknowledgments}

One of us (AB) thanks former coworkers for their invaluable contributions to the development of the dynamic in situ techniques shown in this article. Their names appear in the reference list.

Received: June 25, 2012

[1] G. A. Somorjai, 'Introduction to Surface Chemistry and Catalysis', John Wiley, 1994.

[2] R. J. Meier, Chem. Soc. Rev. 2005, 34, 743.

[3] E. Stavitski, B. M. Weckhuysen, Chem. Soc. Rev. 2010, 39, 4615 .

[4] I. E. Wachs, C. A. Roberts, Chem. Soc. Rev 2010, 39, 5002.

[5] A. Urakawa, T. Bürgi, H. P. Schläpfer, A Baiker, J. Chem. Phys. 2006, 124.

[6] A. Urakawa, N. Maeda, A. Baiker, Angew. Chem. Int. Ed. 2008, 47, 9256.

[7] A. Urakawa, R. Wirz, T. Bürgi, A. Baiker, J. Phys. Chem. B 2003, 107, 13061.

[8] G. Jacobs, B. H. Davis, Appl. Catal. A 2007, 333, 192.

[9] F. C. Meunier, Catal. Today 2010, 155, 164

[10] G. G. Olympiou, C. M. Kalamaras, C. D Zeinalipour-Yazdi, A. M. Efstathiou, Catal. Today 2007, 127, 304

[11] J. Schweicher, A. Bundhoo, A. Frennet, N. Kruse, H. Daly, F. C. Meunier, J. Phys. Chem. C 2010, 114, 2248.

[12] D. Baurecht, U. P. Fringeli, Rev. Sci. Instrum 2001, 72, 3782.

[13] A. Urakawa, T. Bürgi, A. Baiker, Chem. Eng. Sci. 2008, 63, 4902.

[14] S. Naito, S. Aida, T. Kasahara, T. Miyao, Res. Chem. Intermed. 2006, 32, 279.

[15] S. Naito, S. Aida, T. Tsunematsu, T. Miyao, Chem. Lett. 1998, 941.

[16] S. Naito, T. Kasahara, T. Miyao, Catal. Today 2002, 74, 201

[17] C. Li, K. Domen, K. Maruya, T. Onishi, J. Catal. 1993, 141, 540 .

[18] A. Eyssler, E. Kleymenov, A. Kupferschmid, M. Nachtegaal, M. S. Kumar, P. Hug, A. Weidenkaff, D. Ferri, J. Phys. Chem. C 2011, $115,1231$. 